\title{
Microstructural and Microchemical Characterization of Dual Step Aged Alloy X-750 and its Relationship to Environmentally Assisted Cracking
}

George A. Young, Nathan Lewis, Michael Hanson, Wayne Matuszyk, Brian Wiersma, Sergio C. Gonzalez

This report was prepared as an account of work sponsored by the United States Government. Neither the United States, nor the United States Department of Energy, nor any of their employees, nor any of their contractors, subcontractors, or their employees, makes any warranty, express or implied, or assumes any legal liability or responsibility for the accuracy, completeness or usefulness of any information, apparatus, product or process disclosed, or represents that its use would not infringe privately owned rights. 


\title{
Microstructural and Microchemical Characterization of Dual Step Aged Alloy X-750 and its Relationship to Environmentally Assisted Cracking
}

George A. Young, Nathan Lewis, Michael Hanson, Wayne Matuszyk, Brian Wiersma, and Sergio C. Gonzalez Lockheed Martin Corporation

P.O. Box 1072

Schenectady, NY 12301-1072

\begin{abstract}
When exposed to deaerated high purity water, Alloy X-750 is susceptible to both high temperature $\left(>249^{\circ} \mathrm{C}\right)$ intergranular stress corrosion cracking (IGSCC) and intergranular low temperature $\left(<149^{\circ} \mathrm{C}\right)$ fracture (LTF). However, the microstructural and microchemical factors that govern environmentally assisted cracking (EAC) susceptibility are poorly understood. The present study seeks to characterize the grain boundary microstructure and microchemistry in order to gain a better mechanistic understanding of stress corrosion crack initiation, crack growth rate, and low temperature fracture. Light microscopy, scanning electron microscopy, transmission electron microscopy, orientation imaging microscopy, scanning Auger microscopy, and thermal desorption spectroscopy were performed on selected heats of Alloy X-750 AH. These data were correlated to EAC tests performed in $338^{\circ} \mathrm{C}$ deaerated water. Results show that grain boundary $\mathrm{MC}$-type $\{(\mathrm{Ti}, \mathrm{Nb}) \mathrm{C}\}$ carbides and increased levels of grain boundary phosphorus correlate with an increase in LTF susceptibility but have little effect on the number of initiation sites or the SCC crack growth rate. Thermal desorption data show that multiple hydrogen trapping states exist in Alloy X-750 condition AH. Moreover, it appears that exposure to high temperature $\left(>249^{\circ} \mathrm{C}\right)$, hydrogen deaerated water increases the hydrogen concentration in strong hydrogen trap states and degrades the resistance of the material to low temperature fracture. These findings are consistent with a hydrogen embrittlement based mechanism of LTF where intergranular fracture occurs ahead of a crack tip and is exacerbated by phosphorus segregation to grain boundaries and grain boundary hydrogen trap states.
\end{abstract}

\section{Introduction}

Alloy X-750 bar in the dual step aged "AH" heat treatment 'hot rolled $+885^{\circ} \mathrm{C} / 24 \mathrm{hr}$ "stress equalization", air cool + $704^{\circ} \mathrm{C} / 24 \mathrm{hr}$ aging, air cool) is susceptible to EAC when exposed to high purity, hydrogenated water [1-3]. Additionally, significant heat to heat variability in $\mathrm{EAC}$ resistance exists within the AII heat treatment $[2,3]$. While increased levels of grain boundary phosphorus have been correlated to decreased resistance to LTF $[2,4]$, the effects of other microstructural variables such as grain boundary structure, misorientation, and hydrogen trapping remain relatively unexplored.

The EAC test data summarized in Figure 1 show two significant effects: (1) heat \#3 is more susceptible to failure than heats \#1 and \#2 and (2) there appears to be an effect of prior exposure to high temperature water on the failure rate of heat \#3. In order to better understand the factors that affect heat to heat variability and the effect of prior exposure on EAC failures, the microstructure and microchemistry of each material was investigated. Characterization techniques included light microscopy, scanning electron microscopy (SEM), transmission electron microscopy (TEM), orientation imaging microscopy (OIM), scanning Auger microscopy (SAM) and thermal desorption spectroscopy (TDS).

\section{Materials Investigated}

\section{Experimental Procedure}

Three heats of alloy X-750, condition AH were used in these tests. The samples used in this testing were machined from samples which were previously exposed, under stress, to high temperature water $\left(>249^{\circ} \mathrm{C}\right)$ for long times $(\sim 10$ years). Note that the size of the samples that were pre-exposed was sufficiently small that exposure for 10 years is well in excess of the time required to achieve equilibrium of the hydrogen concentration with the water. One heat of material (\#3) was also tested without prior exposure to high temperature water and is designated \#3 NPE for "no prior exposure". 


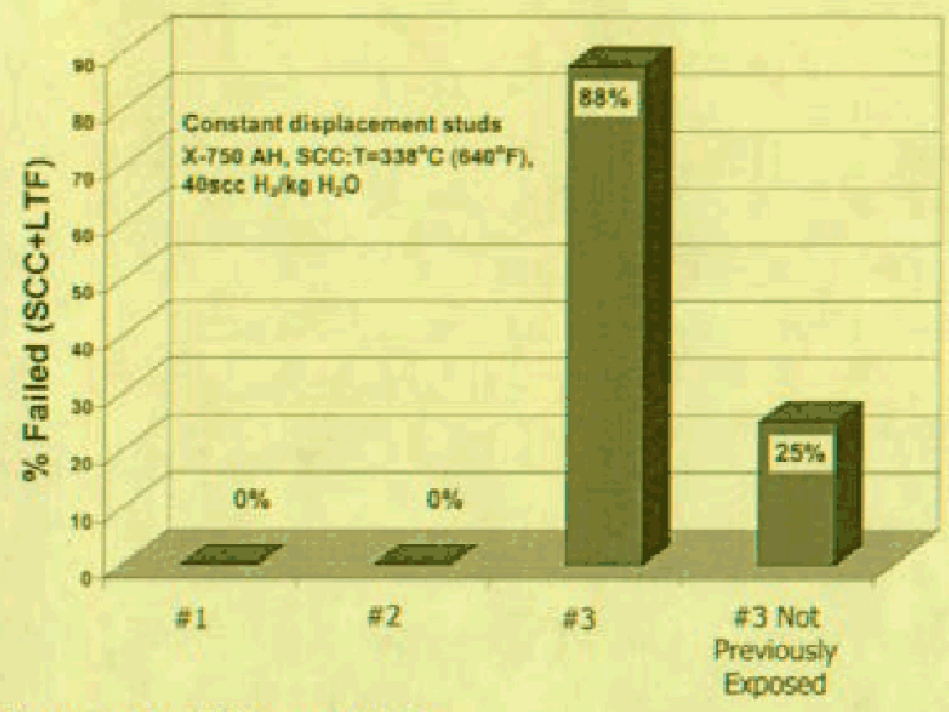

\section{Microstructural Characterization \\ Microstructura}

The microstructure of each heat was characterized via light microscopy, scanning electron microscopy (SEM), orientation imaging microscopy (OLM), and transmission electron microscopy (TEM). Metallographically prepared samples were electrolytically etched in \&:1 phosphoric acid and used for light mieroscopy, SEM, and OIM. The OIM analyses were performed at a commercial laboratory (TexSEM). Foils for TEM analysis were prepared by mechanical grinding and electropolishing ( $20 \%$ perchloric acid in methanol). A Philips CM 300 instrument with a $\mathrm{LaB}_{6}$ filament, operated at $300 \mathrm{keV}$ was used for the TEM studies.

\section{Microchemical Characterization}

The grain boundary chemistry of each heat was quantified via seanning Auger microscopy (SAM). Prior to testing, notched Auger pins were machined from the SCC samples and were precharged in high temperature $\left(371^{\circ} \mathrm{C}\right)$, highpressure ( $5000 \mathrm{psi}$ ) hydrogen gas for 48 hours in order to facilitate intergranular fracture. In-situ fracture was produced by manual, incremental straining of the notched bar via bending. Eight grain facets were investigated via SAM for each heat.

\section{Thermal Desarption Spectroscopy}

The specimens used for desorption experiments were sectioned from the EAC test specimens $\left(-0.37^{\prime \prime} \times 0.25^{\prime \prime} \times 0.19^{\prime \prime}\right)$. Prior to testing the samples were cleaned and dried to prevent any hydrocarbons from biasing the desorption data. The desorption spectra were obtained by heating the specimens (via radio frequency) at $5^{\mathrm{D}} \mathrm{C}$ minute in an ultra-high vacuum system and monitoring the hydrogen concentration (mass/charge-2) with a quadrupole mass spectrometer.

\section{Testing to Assess EAC Performance}

The relative resistance to $\mathrm{SCC}$ initiation, crack growth, and low temperature fracture for $\mathrm{X}-750$ AH were assessed via testing of uniaxially loaded \{net section stress $=448 \mathrm{MPa}$ at $338^{\circ} \mathrm{Cl}, 15.9 \mathrm{~mm}$ diameter, (constant displacement) studs. The details of this type of testing have been described previously [5]. The test specimens were machined from material that had been prior exposed to high temperature water $\left(>249^{\circ} \mathrm{C}\right)$ for long times $(-10$ years). Tests were conducted in $\left(338^{\circ} \mathrm{C}\right)$, high purity water with a hydrogen concentration of $40 \mathrm{scc} / \mathrm{kg}$. The samples were tested for 56 days (or until failure, i.e, the specimens were broken into two pieces) and were periodically inspected at 14-day intervals. The inspections also served as a LTF test since the samples were cooled down to room temperature under load. Note that regions of SCC were distinguished from LTF by the difference in oxide color, i.e. SCC appears dark and LTF appears hight. Low temperature fracture is a rapid $(>-90 \mathrm{~mm} / \mathrm{yr})$, intergranular form of environmentally assisted eracking deseribed elsewhere [2]. 
The number of initiation sites was determined by post-test visual examination at $\sim 10 \mathrm{X}$. Crack growth rates were estimated by dividing the maximum observed SCC length by the exposure time. Determining a crack growth rate is reasonable since (1) crack initiation times are short ( -1 day) for tests under these conditions and (2) the estimated rates are in good agreement with literature data for $\mathrm{X}-750 \mathrm{AH}$ tested under similar conditions $[2,3]$.

\section{Metallography}

\section{Results}

A comparison of the range of grain sizes ebserved in this study is given in Figure 2. The ASTM grain size numbers ranged from 7.2-7.7, which correspond to average grain diameters between 25 and $30 \mu \mathrm{m}$. Note that the $\eta$ phase $\left(\mathrm{Ni}_{3} \mathrm{Ti}_{\mathrm{i}}\right)$ was observed in each heat.

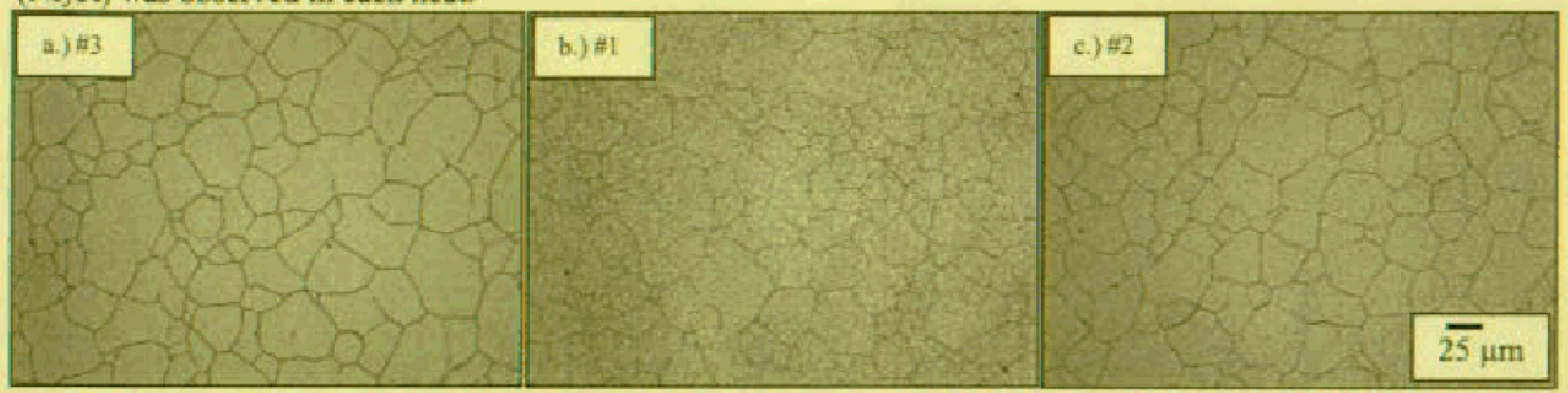

Figure 2. Conparison of the grain structure of the heass of $X-750$.AH invesiggated in this stwity. Electrolytically etched in $8: 1$ phosphoric acid in water, $3 \mathrm{~V}$.

\section{Scanning Eleciron Microscopy}

A higher magnification view of heat \#3 is shown in Figure 3, which shows the presence of $\eta$ phase ( $\mathrm{Ni}_{3} \mathrm{Ti}$, hep crystal structure), large intragranular $\gamma^{\prime}$ (NijAl), MC-type grain boundary carbides and $\gamma^{\prime}$ denuded zones around the $\eta$ and the grain boundaries. Note that the $\eta$ phase was banded in this heat of AH suggesting $\eta$ precipitated along bands rich in titanium.

\section{Transmission Electron Microscopy}

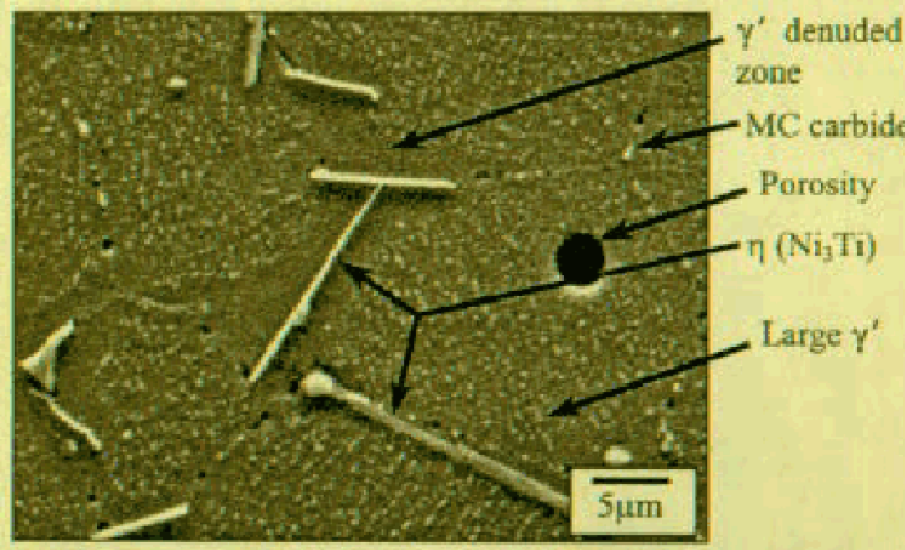

Two of the heats investigated displayed large $\gamma^{\prime}$ on the grain boundary while one heat ( $\# 3$ ) showed predominately MC-type earbides as shown in Figure 4. Note that no difference was observed between \#3. and \#3 NPE. The relatively large amount of $\eta$ phase in this heat may have depleted the matrix in titanium, retarding grain boundary $\gamma^{\prime}$ precipitation and allowed grain boundary MC-type carbides to form during the $885^{\circ} \mathrm{C} / 24$ bour stress equalization heat treatment.
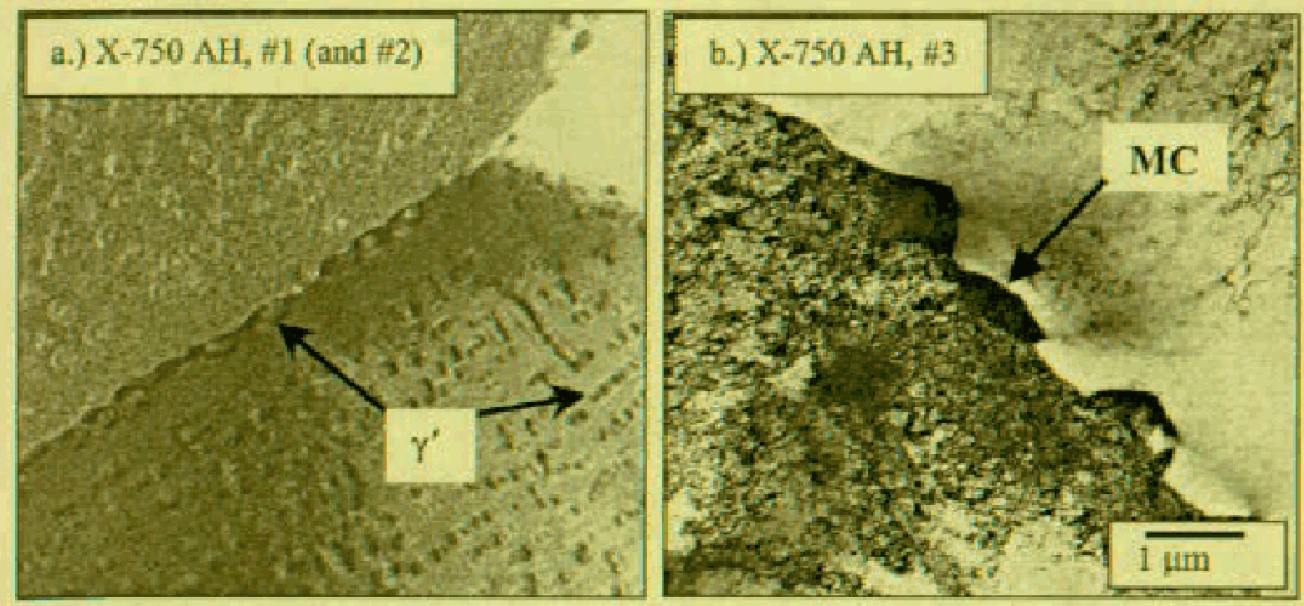

Figure 4. Comparison of the grain boundary microstrictures observed in $X-750$ AH Large grain boundary $\gamma^{*}$ is commonly observed in AH. However, hear it 3 exhibited predominantly $M C$ carbides on the grain boundaries. 


\section{Orientation Imaging Microscopy}

A comparison of the number of $\Sigma 3$ grain boundaries in each heat is shown in Figure 5. The $\mathbf{2 3}$ grain boundaries are used for comparison since other researchers have correlated this boundary type $[6,7]$ in Alloy X-750 and lower strength Ni$\mathrm{Cr}-\mathrm{Fe}$ Alloys with EAC resistance. The misorientation distribution function (MDF) value is defined as the quotient of relative counts (i.e. the fraction of boundaries between adjacent measurements satisfying Brandon's criterion for specialness) to relative volume (the volume of orientation space swept out by the radius defined by Brandon's criterion).

\section{Scanning Auger Microscopy}

Typical scanning electron micrographs of the intergranular fracture surfaces, Auger spectra, and compositional maps are shown in Figures 6 and 7. For each heat, eight intergranular facets from in-situ fractured Auger pins were investigated. The average compositions and standard deviations are reported in Table 1 . Note that heat $\$ 3$ exhibited relatively high levels of carbon (consistent with TEM micrographs showing a high density of MC-carbides) and grain boundary phosphorus.

Table I. Comparison of Grain Boundary Chemistry Determined via Scanning Auger Microscopy

\begin{tabular}{|c|c|c|c|c|c|c|c|c|c|c|}
\hline & Heat & B & C & $\mathbf{P}$ & $\mathbf{S}$ & $\mathbf{T i}$ & $\mathrm{Cr}$ & $\mathrm{Fe}$ & $\mathrm{Ni}$ & $\mathrm{Nb}$ \\
\hline \multirow{2}{*}{$\# 3$} & Mean (at. \%) & 1.4 & 17.0 & 3.3 & 0.2 & 3.3 & 13.1 & 4.7 & 54.9 & 2.2 \\
\hline & St. Dev. & 0.2 & 5.1 & 1.1 & 0.1 & 0.3 & 0.5 & 0.6 & 4.8 & 0.7 \\
\hline \multirow{2}{*}{$\# 1$} & $\operatorname{Mean}(a t . \%)$ & 3.1 & 8.6 & 2.3 & 0.2 & 3.3 & 14.4 & 5.0 & 61.3 & 1.9 \\
\hline & St. Dev. & 0.6 & 4.5 & 0.6 & 0.1 & 0.3 & 1.0 & 0.6 & 3.8 & 0.6 \\
\hline \multirow{2}{*}{$\# 2$} & Mean $(a t . \%)$ & 2.9 & 11.3 & 2.4 & 0.2 & 3.3 & 15.0 & 5.1 & 57.9 & 2.0 \\
\hline & St. Devi & 0.9 & 5.2 & 0.6 & 0.1 & 0.5 & 1.0 & 0.8 & 4.2 & 0.6 \\
\hline
\end{tabular}

\section{Thermal Desorption Spectroscopy (TDS)}

Thermal desorption spectra from each heat are shown in Figure 8. Note that desorption from four distinct states is observed. These data were well fit to asymmetric double sigmoidal shaped curves, indicative of a first order desorption process. The desorption energy from each trap state was then estimated via the method of Lee $\mathrm{e}$ al. [8] (Equation 1) were $E_{\text {Desortion }}$ is the desorption energy, $R$ is the gas conistant, $T_{\operatorname{man}}$ the temperature of the peak maximum, and $B$ is a fitting parameter. Also note the lower hydrogen concentration in heat $\# 3 \mathrm{NPE}$ near the $600^{\circ} \mathrm{C}$ desorption peak.

The value of $B$ was determined for each spectrum by assuming that the lowest temperature peak from each spectrum was representative of desorption from the lattice. The desorption energy from the lattice was taken as $53.0 \mathrm{~kJ} / \mathrm{mol}$ based on the X-750 AH diffusion data of Kishimoto et al. [9]. The binding energies were then calculated via Equation 2 and are summarized in Table II. Note that differential thermal analysis (dlata not shown here) indicated that no phase changes were observed over the temperature range of the TDS tests $\left(25-1000^{\circ} \mathrm{C}\right)$ supporting the simple de-trapping and diffusion assumption of Equation (2).

$$
\begin{aligned}
& E_{\text {Dexarptian }}=R \cdot T_{\max }\left(B \cdot T_{\max }-1\right)
\end{aligned}
$$

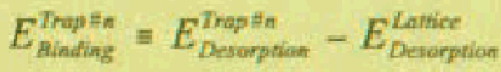



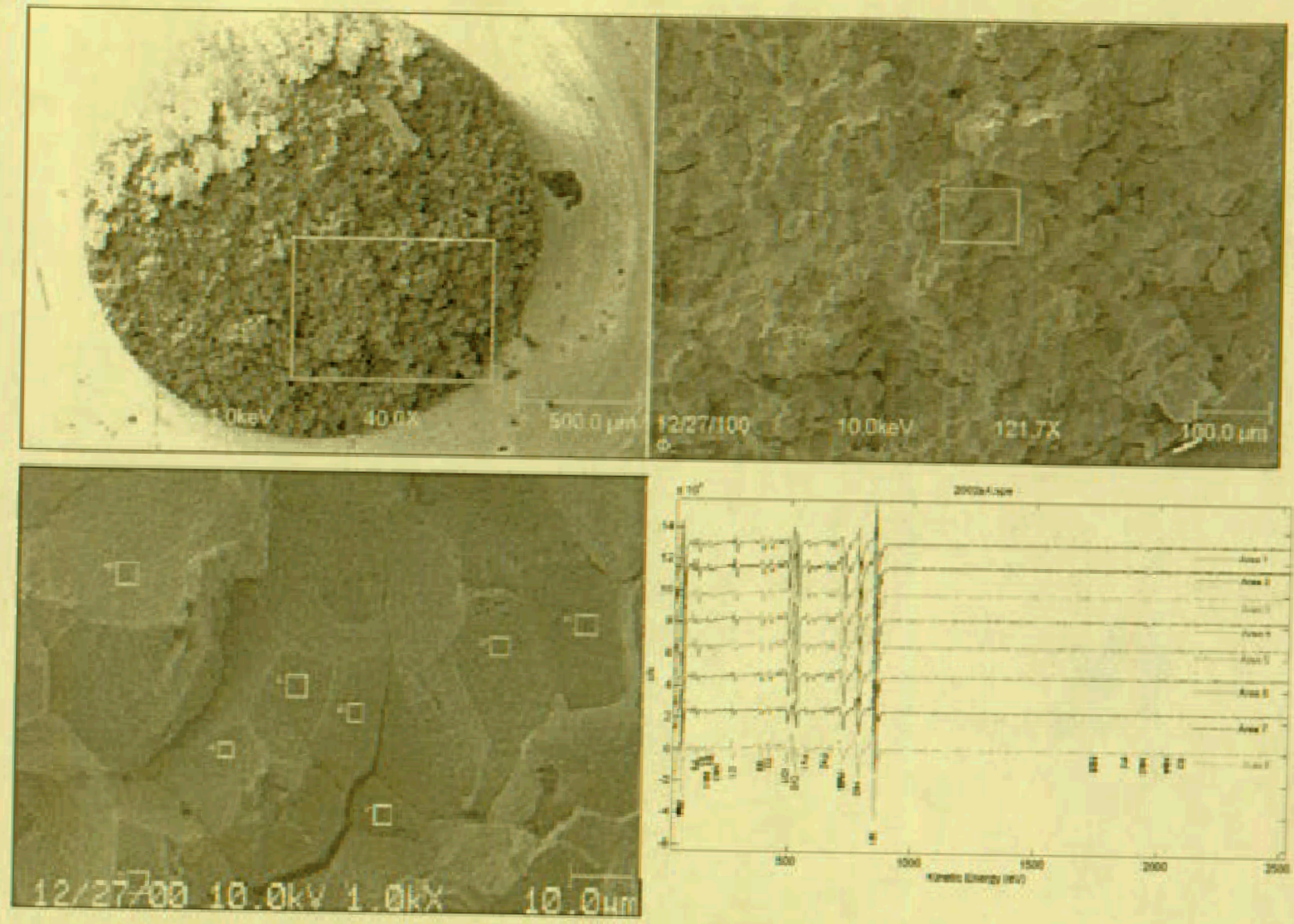

Figure 6. Example of the intergranular fracture produced via in-sim straining and the areas analyred via scanning Auger microscopy (heat \#3).
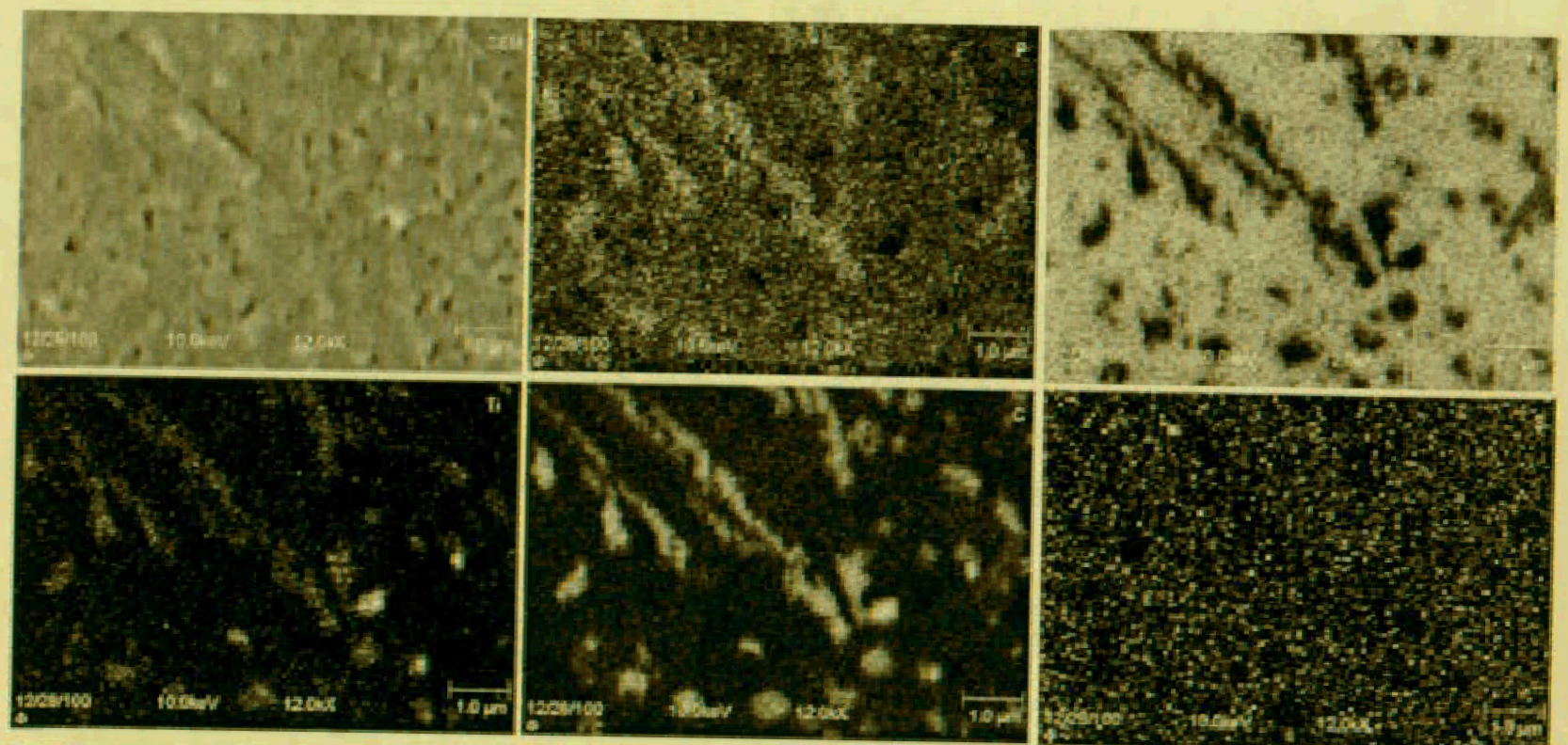

Figure 7. Scanning electron micrograph and elemental maps of an intergranular region of heat \#3. Note that phosphorus appears to be enriched along (TL.NB) C)-type carbides. 

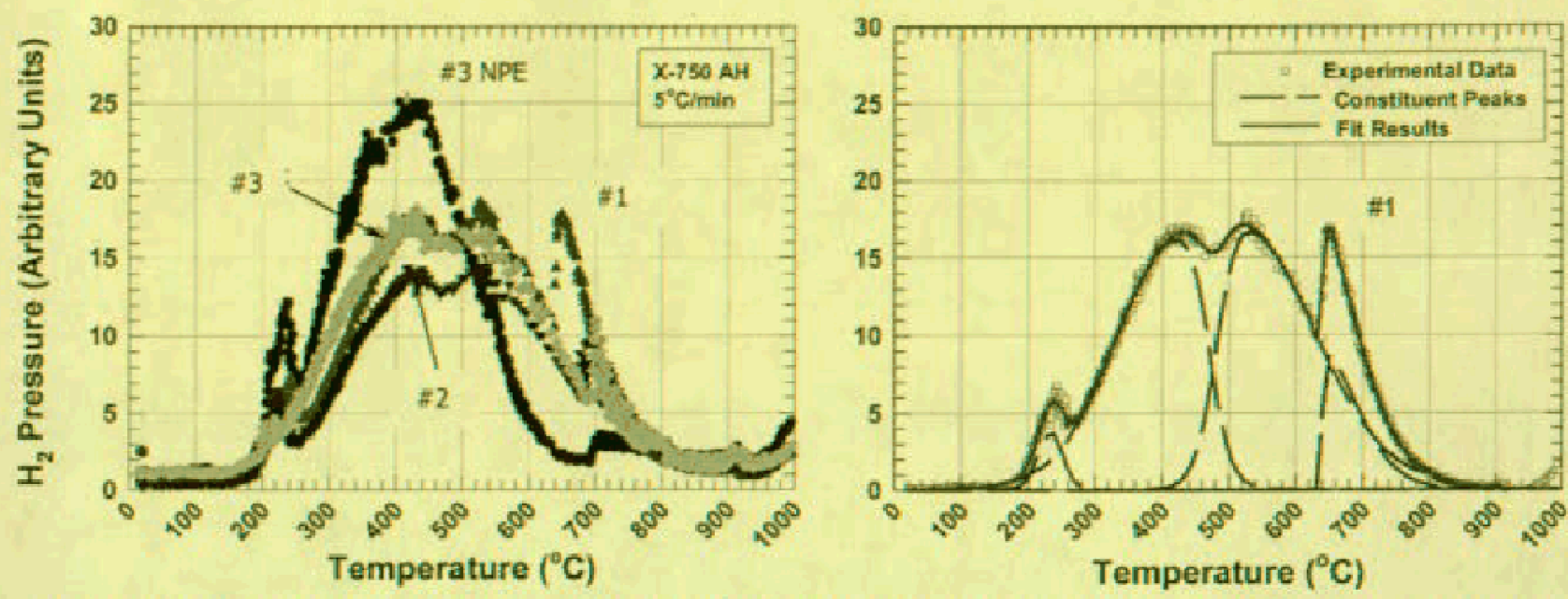

Figure 8. a.) Summary of thermal desorption data and b.t representative data (points), constiturent peak fits (dashed lines) and curve fit (solid line).

Table II. Summary of Thermal Desorption Results

\begin{tabular}{|c|c|c|c|c|}
\hline Heat & $\begin{array}{l}E_{\text {Destire }}^{\text {Lation }} \\
\text { (kJ/mol) }\end{array}$ & $\begin{array}{l}E_{\text {Dheraptian }}^{\text {Trag H }} \gamma^{\prime} \\
\text { (k.J/mol) }\end{array}$ & $\begin{array}{c}E_{\text {Deraption }}^{\text {That }} \\
\mathrm{MC} \text { or } \eta^{\mathrm{q}} \text { ? (kJ/mol) }\end{array}$ & $\begin{array}{c}E_{\text {Deraphiom }}^{\text {Thap }} \\
\eta \text { or } \mathrm{MC} ?(\mathrm{~kJ} / \mathrm{mol})\end{array}$ \\
\hline \#3NPE & \multirow{4}{*}{$\begin{array}{c}53.0 \\
\text { from } \\
\text { Ref. [9] }\end{array}$} & 92.1 & 144.4 & 208.4 \\
\hline$\# 3$ & & 93.0 & 150.8 & 190.2 \\
\hline$\# 1$ & & 89.4 & 138.6 & 189.9 \\
\hline$H 2$ & & 93.7 & 146.6 & 197.0 \\
\hline$E_{\text {Binding }} \pm 1$ St. Dev. & $E_{\text {Binding }}^{\text {Lanice }}=0.0$ & $E_{\text {Binding }}^{\text {Trap M1 }}=39,0 \pm 1,9$ & $E_{\text {Binding }}^{\text {Trap HI }}=92.1+5.1$ & $E_{\text {Binding }}^{\text {Thaph }}=143,4 \pm 8.6$ \\
\hline
\end{tabular}

\section{Tesing to Assess EAC Performance}

The relative resistance to SCC initiation, crack growth, and low temperature fracture for X-750 AH are compared in Table III. Note that while the number of SCC sites and crack growth rates are similar, there is a large difference in LTF susceptibility between heats. Additionally, there is a significant difference in the number of LTF failures for the same heat $\# 3$ with and without prior exposure to $>249^{\circ} \mathrm{C}$ ) water for $\sim 10$ years.

Table III. Comparison of EAC Resistance of the Three Heats of Alloy X-750 AH Investigated

\begin{tabular}{cccc}
\hline Heat \# & $\begin{array}{c}\text { \# of SCC Sites per } \\
\text { Day of Exposure }\end{array}$ & $\begin{array}{c}\text { Crack Growth } \\
\text { Rate* }(\mathbf{m m} / \mathrm{yr})\end{array}$ & $\begin{array}{c}\text { LTF Susceptibility } \\
\text { (\% Falled) }\end{array}$ \\
\hline \#3 NPE & $0.52 \pm 0.22$ & $9.64 \pm 5.01$ & 25 \\
\#3 & $0.47 \pm 0.29$ & $8.44 \pm 2.13$ & 88 \\
\#1 & $0.44 \pm 0.13$ & $8.53 \pm 0.46$ & 0 \\
\#2 & $0.42 \pm 0.11$ & $8.90 \pm 0.83$ & 0 \\
\hline
\end{tabular}

"Crack growth rates were estimated from the maximum observed crack length ( $\Delta a)$ divided by the total exposure time ( $\Delta \mathrm{t}$ ) 


\section{Discussion}

\section{Summary of Key Findings}

Analysis of the number of SCC initiation sites, crack growth rates and number of failures (Figure 1 and Table III) shows that the increased tendency of heat $\# 3$ to fail is due to a decreased resistance to low temperature fracture. Between heats, no significant difference in the number of SCC initiation sites or crack growth rate was observed. Microstructurally, heat \#3 shows an unusually high degree of MC-type grain boundary carbides as well as increased levels of grain boundary phosphorus as compared to heats $\# 1$ and $\# 2$. While heat $\# 3$ also has the fewest number of $\Sigma 3$-type grain boundaries, the difference between heats is small and likely is not a significant factor in the LTF resistance.

Thermal desorption tests show that at least four distinct hydrogen trapping states exists in X-750 AH. The lowest energy state is assumed to be desorption from the octahedral interstices of the lattice. The next lowest energy state has a binding energy $\sim 39 \mathrm{~kJ} / \mathrm{mol}$ which is in good agreement with Turnbull's calculation ( $37 \mathrm{~kJ} / \mathrm{mol}$ ) of the binding energy of hydrogen to $\gamma^{\prime}$ in $\mathrm{X}-750 \mathrm{AH}[10]$. The two remaining desorption states are strong hydrogen traps with binding energies of $\sim 92$ and $143 \mathrm{~kJ} / \mathrm{mol}$. Possible trapping states include MC carbide/lattice and $\eta /$ lattice interfaces.

Table IV. Comparison of LTF Susceptibility and Selected Microstructural and Microchemical Findings

\begin{tabular}{cccccc}
\hline Heat \# & $\begin{array}{c}\text { LTF } \\
\text { Susceptibility } \\
\text { (\% Failed) }\end{array}$ & $\begin{array}{c}\text { Grain } \\
\text { Boundary } \\
\text { Structure }\end{array}$ & $\begin{array}{c}\text { Avg. GB } \\
\text { Phosphorus } \\
\text { (at.\%) }\end{array}$ & $\begin{array}{c}\Sigma 3 \\
\text { Boundaries }\end{array}$ & $\begin{array}{c}E_{\text {Binding }} \\
\text { Grain Boundary } \\
\text { Traps (kJ/mol) }\end{array}$ \\
\hline \#3 NPE & 25 & MC & --- & -- & 92.1 \\
$\# 3$ & 88 & MC & 3.3 & 23.6 & 92.1 \\
$\# 1$ & 0 & Large $\gamma^{\prime}$ & 2.3 & 24.2 & 39.0 \\
$\# 2$ & 0 & Large $\gamma^{\prime}$ & 2.4 & 25.5 & 39.0 \\
\hline
\end{tabular}

\section{Factors Affecting the Increased Failure Rate of Heat \#3}

Previous research has shown that MC carbides preferentially corrode in primary water and this may help explain the difference in crack growth rate between fast cracking $(\mathrm{AH})$ and slow cracking (HTH) heat treatments of X-750 [3]. However, within the $\mathrm{AH}$ heat treatment, the large difference in grain boundary carbide coverage between heats \#2, $\# 1$ and $\# 3$ has little effect $(<2 \mathrm{X})$ on the apparent crack growth rate (Table IV). Instead, the dominant effect of MC carbides appears to be the decreased resistance to low temperature fracture. Heat \#3 is most susceptible with $88 \%$ of the samples failing, while heats \#2 (0\% failed) and \#1 (0\% failed) are resistant to low temperature fracture.

Recall that heats $\# 2$ and \#1 displayed predominantly $\gamma^{\prime}$ on the grain boundaries while heat \#3 displayed MC-type $(\mathrm{Ti}, \mathrm{Nb}) \mathrm{C}$ carbides on the grain boundaries (Figure 4). As shown by the thermal desorption data, incoherent $\mathrm{MC}$ carbides are strong hydrogen trap states and promote hydrogen segregation to grain boundaries. Increased grain boundary hydrogen concentrations promote intergranular fracture (i.e. LTF).

In addition to hydrogen embrittlement, segregation of metalloids (especially phosphorus) to X-750 grain boundaries has been implicated in lowering the resistance of $X-750$ to LTF $[2,4,11]$. Phosphorus may degrade LTF resistance by both (1) enhancing hydrogen uptake via poisoning the recombination reaction [12] and (2) lowering the cohesive strength of the grain boundary [11]. Note that phosphorus appears concentrated at MC-type carbides as shown in Figure 7, consistent with other Auger studies on X-750 [2]. The increased susceptibility of heat \#3 relative to the other two heats may be explained by its relatively high levels of phosphorus (3.3 at. \%) vs. heats $\# 1(2.3$ at. $\%)$ and $\# 2$ (2.4 at.\%) which is consistent with previous work on X-750 by Grove [4] and Mills [2]. While the increased grain boundary phosphorus concentration in heat \#3 may appear modest, work by Grove and Petzold [4] on X-750 Condition $\mathrm{BH}$ (hot rolled $+1300^{\circ} \mathrm{F} / 20 \mathrm{hrs}$ ), indicates that an increase from 2.3 to 3.3 at. \% can decrease the LTF resistance by $\sim 30 \%$ as shown in Figure 9. 
Atomistic modeling work of Geng et al. [11], on $\Sigma 5$ nickel grain boundaries provides a basis to assess the combined effects of grain boundary impurities on the grain boundary cohesive strength. Consistent with experimental observations [13], atomistic calculations show that hydrogen, and phosphorus decrease grain boundary cohesion ( $\Delta E_{\text {Strengthening }}$ is $<0$ ), while boron increases cohesion ( $\angle E_{\text {Strengthening }}$ is $>0$ ). This work also suggests that $\mathrm{Be}$ and $\mathrm{C}$ should enhance cohesion while $\mathrm{S}, \mathrm{AI}$, and $\mathrm{Si}$ should decrease grain boundary cohesion, although the magnitude of the effect of these elements was not calculated. Normalizing the Geng data by the absolute value of the strengthening energy of hydrogen suggests an equation of the form of Equation 3. In Equation 3, the symbols in brackets represent the free concentration of those species on the grain boundary (atoms per atom of $\mathrm{Ni}$ ) and the prefactors are normalized to the strength of hydrogen

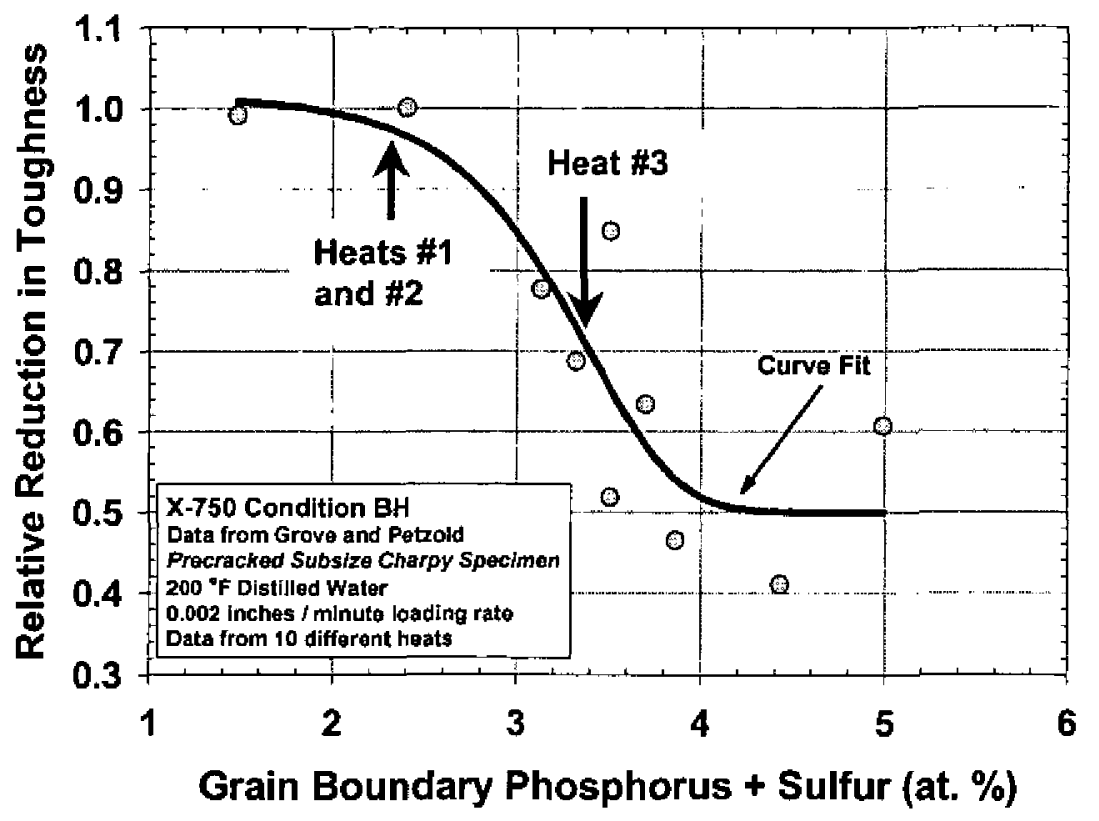

Figure 9. Illustration of the effect of grain boundary phosphorus and sulfur on the low temperature fracture resistance of Alloy $X-750 \mathrm{BH}$. The data were taken from Reference 4.

$$
\begin{aligned}
& \text { (i.e. } \left.\Delta E_{\text {Sirengthening }}^{\text {Phosphorous }} /\left|\Delta E_{\text {Strengthening }}^{\text {Hydrogen }}\right|=-2.6\right) \\
& \qquad \Delta E_{\text {Strengthing }}^{\text {Nickel } \Sigma 5} \approx-1 \cdot[H]-2.6 \cdot[P]+1.8 \cdot[B]
\end{aligned}
$$

While Equation 3 does not include all relevant segregants (such as sulfur and carbon) or include the complexities of alloying additions or second phase particles, it is useful to assess the combined effects of hydrogen, phosphorus and boron. At a given hydrogen concentration, Equation 3 predicts that the grain boundary cohesive strength of each heat should be $\# 2 \cdot(-1.7)>\# 1(-4.0)>\# 3(-6.1)$. This analysis re-emphasizes the susceptibility of heat \#3 relative to heats $\# 1$ and $\# 2$.

\section{Factors Affecting Decreased LTF Resistance of Prior Exposed Heat \#3}

The increased failure rate of heat $\# 3$ that had prior exposure to high purity water $\left(>249^{\circ} \mathrm{C}, \sim 10\right.$ years) suggests that prior exposure degrades the materials resistance to low temperature fracture. The thermal desorption data shown in Figure 8 gives a possible basis for explaining the increased failure rate. Note that all the prior exposed material shows increased amounts of hydrogen (given by the area under the desorption curves) at high temperatures relative to the material that was not prior exposed. Specifically, the trapping state associated with MC-type carbides (i.e. the $540^{\circ} \mathrm{C}$ peak) shows approximately 9 times more hydrogen for prior exposed heat \#3. This increase in $\mathrm{MC}$ carbide hydrogen coverage indicates that prior exposure to high purity water increases the hydrogen concentration in strong trapping states and lowers the resistance of $\mathrm{X}-750 \mathrm{AH}$ to low temperature fracture.

Note that the dissolved hydrogen concentration in the water exhibits a maximum near $235^{\circ} \mathrm{C}$, which may in part, explain why material that was prior exposed at $\sim 250^{\circ} \mathrm{C}$ shows increased amounts of trapped hydrogen relative to material that was exposed to $338^{\circ} \mathrm{C}$ water. The equilibrium concentration of hydrogen dissolved in X-750 via Henry's and Sievert's laws [9] is shown in Figure 10. 
At a constant dissolved hydrogen gas concentration of $40 \mathrm{scc} / \mathrm{kg}$, the equilibrium concentration in the metal is greater for the prior exposure temperature $\left(250^{\circ} \mathrm{C}, 2.8\right.$ wt. ppm) than the $\mathrm{SCC}$ testing temperature $\left(338^{\circ} \mathrm{C}, 2.4\right.$ wt. ppm). Additionally, corrosion generated hydrogen during prior exposure may also act to increase the trapped hydrogen concentration relative to material without prior exposure. Another factor that must be considered is the effect of previous exposure on the grain boundary composition. While additional grain boundary phosphons segregation during prior exposure at $>249^{\circ} \mathrm{C}$ ) is possible, kinetic calculations using the diffusivity data for phosphorus in Alloy 600 [14] indicate that segregation at this temperature is extremely slow $\left(D \sim 1 \times 10^{-28} \mathrm{~m}^{2} / \mathrm{sec}\right.$ ), and segregation is unlikely.

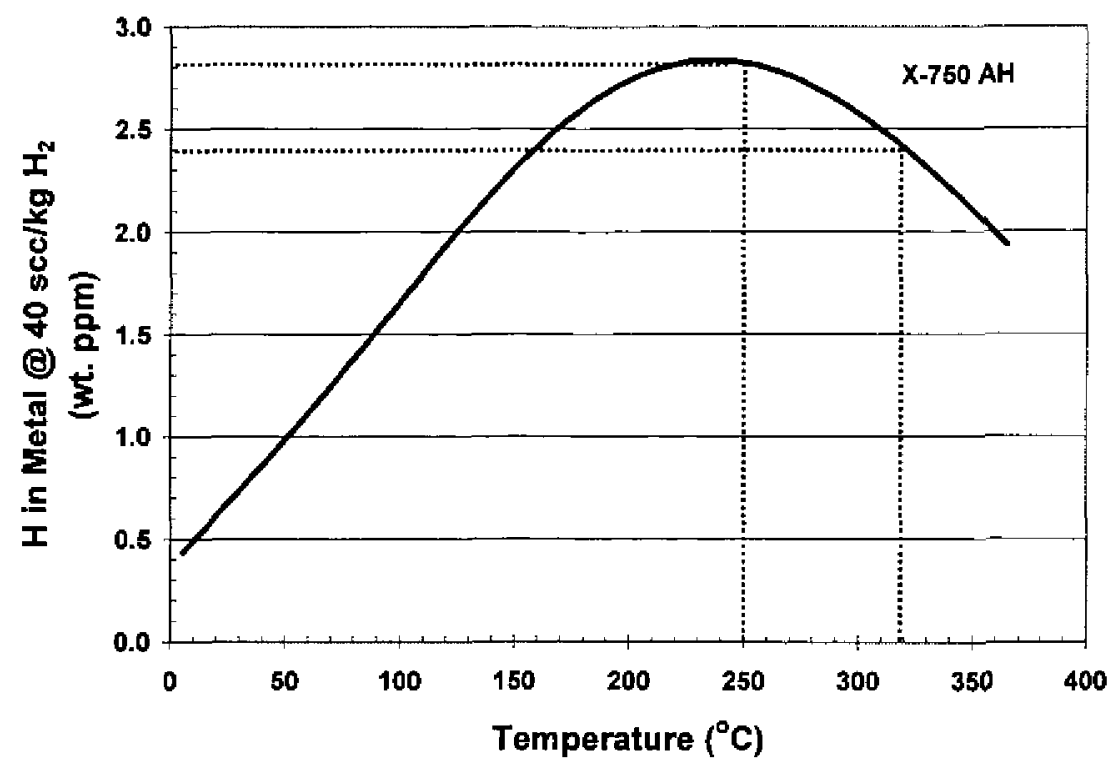

Figure 10. Illustration of the equilibrium hydrogen concentration of hydrogen in $X-750 \mathrm{AH}$ calculated from Henry's and Sievert's laws.

\section{Conclusions}

- Low LTF resistance correlates with a high degree of grain boundary MC-type carbides and increased levels of grain boundary phosphorus.

- Grain boundary MC carbides and grain boundary phosphorus do not appear to have large effects $(<2 \mathrm{X})$ on the number of SCC initiation sites or the SCC crack growth rate in high purity water at $338^{\circ} \mathrm{C}$.

- Grain boundary MC carbides are strong hydrogen traps that promote hydrogen enrichment and embrittlement of the X-750 AH grain boundaries.

- Grain boundary phosphorus may degrade LTF resistance by both enhancing hydrogen uptake and lowering the cohesive energy of the grain boundary.

- Exposure to high temperature water $\left(>249^{\circ} \mathrm{C}\right)$ for extended times $(-10$ years) appears to degrade the low temperature fracture resistance of X-750 AH. This degradation may be due, in part, to an increased hydrogen concentration at grain boundary MC-type carbide trapping states.

\section{Acknowledgements}

The Authors wish to thank Al Kephart, Paul Lozier, Nick Panayotou, Debbie Perry, and Tom Wong of the Lockheed Martin Corporation for their many helpful discussions. Dr. Vince Smentkowski of the General Electric Corporate Research and Development Laboratory performed the thermal desorption testing. 


\section{References}

1. Hanninen, H. and I. Aho-Mantila. Environment-Sensitive Cracking of Reactor Internals. in Environmental Degradation of Materials in Nuclear Power Systems-Water Reactors. 1988. Michigan: TMS.

2. Mills, W.J., M.R. Lebo, and J.J. Kearns, Hydrogen Embrittlement, Grain Boundary Segregation, and Stress Corrosion Cracking of Alloy $X-750$ in Low and High-Temperature Water. Met. Trans. A, 1999. 30A: p. 15791596.

3. Fish, J.S., et al. AEM Investigation of Primary Water SCC in Nickel Alloys. in The Eighth International Symposium on Environmental Degradation of Materials in Nuclear Power Systems-Water Reactors. 1997. Amelia Island, FL: American Nuclear Society, p. 266-273.

4. Grove, C.A. and L.D. Petzold, Mechanisms of Stress-Corrosion Cracking of Alloy X-750 in High-Purity Water. J. Materials. for Energy Systems, 1985. 7(2): p. 147-162.

5. Kephart, A.R. and S.Z. Hayden. Benefits of Thread Rolling Process to the Stress Corrosion Cracking and Fatigue Resistance of High Strength Fasteners. in The Sixth International Symposium on Environmental Degradation of Materials in Nuclear Power Systems-Water Reactors. 1993: TMS, p. 805-813.

6. Pan, Y., et al., Grain-Boundary Structure Effects on Intergranular Stress Corrosion Cracking of Alloy $X-750$. Acta Mater., 1996. 44(12): p. 4685-4695.

7. Crawford, D.C. and G.S. Was, The Role of Grain Boundary Misorientation in Intergranular Cracking of Ni16Cr-9Fe in 360 ${ }^{\circ} \mathrm{C}$ Argon and High Purity Water. Met. Trans. A, 1992. 23A: p. 1195-1206.

8. Lee, K.Y., J. Lee, and D.R. Kim, A Study of Hydrogen-trapping Phenomena in AISI 5160 Spring Steel. Mat. Sci. Eng., 1984. 67: p. 213-220.

9. Kishimoto, N., et al., Hydrogen Diffusion and Solution at High Temperatures in 316L Stainless Steel and Nickel-Base Heat-Resistant Alloys. J. Nuclear Mat., 1985. 127: p. 1-9.

10. Turnbull, A., et al., Hydrogen Transport in Nickel-Base Alloys. Met. Trans. A, 1992. 23A: p. 3213-3244.

11. Geng, W.T., et al., Embrittling and Strengthening Effects of Hydrogen, Boron, and Phosphorus on a 25 Nickel Grain Boundary. Phys. Rev. B, 1999. 60(10): p. 7149-7155.

12. McCright, R.D. Effects of Environmental Species and Metallurgical Structure on the Hydrogen Entry into Steel. in Stress Corrosion Cracking and Hydrogen Embrittlement of Iron Base Alloys. 1973. Firminy, France: NACE.

13. Jones, R.H. and S.M. Bruemmer, Environment-Induced Crack Growth Processes in Nickel-Base Alloys, in Environment-Induced Cracking of Metals, R.P. Gangloff and M.B. Ives, Editors. 1988, NACE. p. 287-310.

14. Guttmann, M., et al., An Auger Electron Spectroscopic Study of Phosphorus Segregation in the Grain Boundaries of Nickel Base Alloy 600. Comosion, 1981. 37: p. 416-425. 